\title{
Uma leitura de Insânia, de Hélia Correia
}

Simara Aparecida Ribeiro Januário Mestre em Letras: Estudos Literários (Literatura Brasileira) / UFMG

\begin{abstract}
RESUMO
A leitura de Insânia, da autora portuguesa Hélia Correia, permite identificar no jogo de esconder a personagem Natalina (personificação da loucura) o próprio jogo da autora para driblar o que Barthes chama de "fascismo da linguagem” e também como forma de realização do discurso amoroso barthesiano, no qual o ato de escrever é visto como uma grande impossibilidade.
\end{abstract}

\section{PALAVRAS-CHAVE}

Hélia Correia, Insânia, discurso amoroso

A escritora lisboeta Hélia Correia é autora de uma vasta bibliografia: o livro infantil $A$ luz de Newton: 7 histórias de cores (1988); as obras de ficção O separar das águas (1981), O número dos vivos (1982), Montedemo (1983), Villa celeste (1985), Soma (1987), A fenda erótica (1988), A casa eterna (1991), Insânia (1996), Lillias Fraser (2001) e Apodera-te de mim (2002); o livro de poemas A pequena morte / esse eterno canto (1986) e as obras de teatro Perdição, exercício sobre Antígona (1991), Florbela (1991), O rancor, exercício sobre Helena (2000) e O segredo de Chantel (2005).

Neste artigo faremos uma leitura de Insânia, livro que trabalha a questão da demência, da loucura, e no qual pretendemos identificar a tentativa de Hélia Correia de driblar o que Barthes chama de fascismo da linguagem a partir do tratamento dado à personagem Natalina, que associamos à loucura, e também como forma de atingir a realização do discurso amoroso barthesiano, no qual o ato de escrever é visto como uma grande impossibilidade.

O dicionário Houaiss define o termo “insânia” como “condição do que é ou está insano, loucura, demência, insanidade, ação insana ou desatino”. ${ }^{1}$ Nesse sentido, o título do

\footnotetext{
${ }^{1}$ HOUAISS; VILLAR; FRANCO. Dicionário eletrônico Houaiss da língua portuguesa, p. 1, 623.
} 
livro inicialmente nos remete à ideia de que o assunto tratado é a loucura, conceito básico do termo "insânia"; mas percebemos, no decorrer do texto, que a acepção desse termo é expandida, rompendo os limites de significação impostos pela própria língua. É possível o deslocamento do signo insânia, alargando sua significação: o livro não se refere apenas à insanidade como uma patologia mental, mas também descreve o dia a dia da aldeia da Levada, lugar permeado por acontecimentos anormais ligados à menina Natalina, que parece trazer consigo a loucura.

Podemos interpretar o título do livro, então, como a insanidade ou desatino que se instala na aldeia, e, consequentemente, em seus habitantes, mas também como um nome próprio que pode ser considerado a designação de Natalina, pois a menina parece estar associada à loucura, visto que ela desencadeia uma série de anormalidades nos ambientes onde frequenta.

Hélia Correia afirmou, não desconsidera, conforme afirmou em entrevista dada à professora Lúcia Castello Branco, ${ }^{2}$ a limitação do signo linguístico que deixa de lado, devido ao autoritarismo da língua, uma realidade que há para além das palavras. Percebe-se que a autora de Insânia não exclui de forma alguma a expansão significativa do signo através do deslocamento do mesmo, fato perceptível no título do livro que estamos abordando.

De acordo com Roland Barthes, o poder é algo que está presente nos diversos meios sociais, incluindo aqueles nos quais nunca se imagina encontrá-lo. É possível vê-lo inserido em um objeto que acompanha o homem desde o início de sua história: a linguagem. O poder se manifesta na língua através das imposições que faz ao falante, obrigando-o a dizer algo limitado, que não encerra em si tudo aquilo que o indivíduo possuía em mente e desejava transmitir ao interlocutor quando emitiu um enunciado. A partir disso, o estudioso afirma que falar não é simplesmente comunicar-se, e, sim, se sujeitar ao dito "fascismo" característico da língua. Esse autoritarismo da linguagem é claramente perceptível através do signo gregário, que carrega consigo um estereótipo de significação, ao qual o falante subjuga-se. Barthes conclui, então, que não existe liberdade senão fora da linguagem, e o único mecanismo que permite ouvi-la fora do poder é a literatura.

Nesse sentido, Hélia Correia parece ser adepta das ideias de Barthes acerca do fascismo da linguagem e do desvio das imposições feitas pela mesma, pois afirma que:

Se brincarmos bastante, ficaremos libertos da doença do pensamento linear, da organização seqüencial e significante dos sons. Chegará o momento em

\footnotetext{
${ }^{2}$ BRANCO. Encontro com escritoras portuguesas, p. 103-114.
} 
que a linguagem se nos tornará estranha, a ponto de não mais a reconhecermos. Terá perdido assim o seu poder. ${ }^{3}$

O livro Insânia nos conta a história de Natalina, menina que é “encontrada”, numa dobra de caminho, estéril e infértil, por Francisco Amor, que, desde criança, tem contato com as profecias apocalípticas e, já adulto, assiste na televisão notícias que não entendia. Não as entendia porque estavam em outras línguas e ele não confiava nas notícias em português. Esse personagem é um homem confuso que não confia em sua própria língua: "Mas Francisco inquietava-se, temendo que as coisas estivessem a passar-se e a serem transmitidas noutro lado. Não confiava em jornalistas."4

No caminho desse homem assustado, solitário e atormentado, atravessa Natalina e, através dele, se infiltra na Levada. Essa menina, quase sem corpo, pode ser considerada como a personificação da loucura, da demência, da insânia. Uma das definições da palavra "corpo" é um "grupo de pessoas consideradas como unidade ou como conjunto organizado". 5 Dessa forma, Natalina se corporifica nesse grupo de pessoas que habitam a incomum aldeia, desencadeando situações inusitadas, como o jogo de escondê-la. Jogo que os envolve em uma trama para enganar os “Amores canadianos”, modo com são tratados o filho, a nora e os netos de Francisco Amor, porque moravam a tempos no Canadá.

O jogo é prazeroso para os levadeiros, pois através dele existe a cumplicidade, o regozijo em ludibriar os que vêm de fora. Percebe-se, aqui, o contraste entre o interno e o externo: "Para a recém-chegada família dos Amores, toda a aldeia, a começar dos velhos pais, parecia atingida por doença (...).”6 A personagem Sandrinha põe um ponto final nesse jogo de esconder Natalina:

E assim foi que agarrou em Natalina e começou a passear com ela, como que numa ausência de cuidados que parecia natural, não fosse o caso de todos evitarem o ar livre. Tinha na idéia que os canadianos acabariam fatalmente por as ver e perguntar acerca da menina. ${ }^{7}$

Dessa forma, Natalina também irá estender sua influência sobre o externo à aldeia. Porém, esse externo é de certa forma pertencente à Levada, uma vez que Francisco Amor

\footnotetext{
${ }^{3}$ CORREIA. A escrita insuportável, p. 172.

${ }^{4}$ CORREIA. A escrita insuportável, p. 9.

${ }^{5}$ FERREIRA. Mini Aurélio - século XXI, p. 187.

${ }^{6}$ CORREIA. Insânia, p. 51.

${ }^{7}$ CORREIA. Insânia, p. 59.
} 
Júnior é natural da aldeia e retorna à casa dos pais, o interno, para também ser levado pela menina ao enlouquecimento.

Roland Barthes, em Fragmentos de um discurso amoroso, considera que o

Saber que não se escreve para o outro, saber que as coisas que vou escrever não me farão nunca amado por aquele que amo, saber que a escritura não compensa nada, não sublima nada, que ela está precisamente aí onde você não está - é o começo da escritura. ${ }^{8}$

Ainda refletindo sobre o processo da escrita, o autor francês destaca, em "Escrever, verbo intransitivo?”, que é “(...) no escrever médio da modernidade, o sujeito constitui-se como imediatamente contemporâneo da escritura, efetuando-se e afetando-se por ela (...).”9 Também conjeturando acerca da escrita, a escritora francesa Marguerite Duras faz a seguinte afirmação:

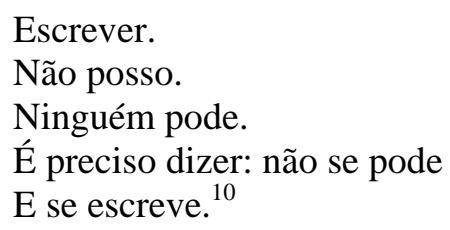

Podemos perceber que tanto para Roland Barthes, quanto para Marguerite Duras, escrever é uma grande impossibilidade. Contudo, a busca dessa impossibilidade se faz necessária, uma vez que o ato de escrever "se atravessa no caminho" do escritor e, apesar da necessidade de dizer que não se pode escrever, de acordo com Duras, acaba-se por fazê-lo.

Esse “atravessar o caminho”, essa urgência, esse efetuar-se e afetar-se pela escrita, conforme Barthes, essa impossibilidade se fazem presentes em Insânia. A primeira frase do livro - “Ao que se saiba, tudo aconteceu por mera negligência” 11 - já aponta para esse caráter de improviso, de eterna tentativa de alcançar o lugar “onde você não está.” Conforme dissemos, em Insânia, a autora trabalha a questão da demência e da loucura. No jogo de esconder Natalina, que os outros personagens fazem, temos o próprio jogo da autora para tentar sublimar, compensar o que não se pode, pois escrever nada sublima e não diminui a dor de sua impossibilidade.

Ao considerarmos a personagem Natalina como a personificação, a materialização da loucura, que podemos tomar também como a "loucura pela escrita”, percebemos que Hélia

\footnotetext{
${ }^{8}$ BARTHES. Fragmentos de um discurso amoroso, p. 93.

${ }^{9}$ BARTHES. Escrever, verbo intransitivo?, p. 38.

${ }^{10}$ DURAS. Escrever, p. 47.

${ }^{11}$ CORREIA. Insânia, p. 9.
} 
Correia também trabalha a questão, a exemplo de Barthes, do discurso amoroso. Dessa forma, a autora toca no impossível ao dizer: "morre, pois, o tecido da história à nossa volta, por mais que nos viremos em busca de socorro, humilhando-nos mesmo à espera de que ele chegue de onde nenhum proveito ainda nos chegou (...).",12

Mas a autora apenas toca, levemente, nessa impossibilidade, nesse lugar do qual nenhum proveito chegou, lugar onde ela não está, lugar da escrita. O livro é constituído de fragmentos de um discurso coletivo dos habitantes da aldeia da Levada, que não é o lugar nem do eu nem do tu, mas do ele, ou melhor, ela, Natalina (ou a loucura) não importa.

A escrita de Hélia Correia é movida pelo discurso amoroso, amoroso aqui no sentido do amor à impossibilidade que reside no ato de escrever. Não e à toa que Hélia dá aos personagens centrais do acolhimento e disseminação de Natalina (ou da loucura) o sobrenome Amor.

É precisamente através do espaço que se dá a eles, dentro do espaço de escrita do livro, que, como explica Barthes, a narrativa de Insânia se move e tanta exprimir o impossível de ser exprimido e se coloca no escrever médio para realizar a impossibilidade de fazê-lo. Sendo assim, a autora o faz não para compensar, diminuir nada nem para os outros: “(...) percebeu que aquilo não tinha a mínima importância para ninguém”, ${ }^{13}$ mas para a representação da própria escrita, que é essencialmente sem destinatário e que somente é tocada pelo escritor, no momento em que ele escreve.

E, sendo essa escrita movida, conforme já dissemos, pelo amor que reside na impossibilidade do ato de escrever, Hélia Correia cria em Insânia um jogo de possibilidades de leitura, que podem apontar para a loucura de toda a Levada, para a personificação da insanidade em Natalina, ou para nenhuma dessas possibilidades.

\begin{abstract}
Reading Insânia, by the Portuguese author Hélia Correia, allows us to identify in the play of hiding the character Natalina (a personification of madness) the author's own play to overcome what Barthes calls the fascism of language and also a way of enacting Barthes's discourse of love, in which the act of writing is seen as a great impossibility.
\end{abstract}

\footnotetext{
${ }^{12}$ CORREIA. Insânia, p. 146.

${ }^{13}$ CORREIA. Insânia, p. 225.
} 


\section{KEYWORDS}

Hélia Correia, Insânia, discourse of love

\section{REFERÊNCIAS}

BARTHES, Roland. Aula. Trad. Leyla Perrone-Moisés. São Paulo: Cultrix, 1978.

BARTHES, Roland. Escrever, verbo intransitivo? In: O rumor da língua. Trad. Mário Laranjeira. São Paulo: Brasiliense, 1988. p. 30-39.

BARTHES, Roland. Fragmentos de um discurso amoroso. Trad. Hortência dos Santos. 4. ed. São Paulo: Francisco Alves, 1984.

BRANCO, Lúcia Castello. Encontro com escritoras portuguesas. Boletim/CESP, Belo Horizonte, v. 13, n. 16, p. 103-114, jul./dez. 1993.

CORREIA, Hélia. A escrita insuportável. In: BRANCO, Lúcia Castello; BRANDÃO, Ruth Silviano (Org.). A força da letra: estilo e representação. Belo Horizonte: Editora UFMG, 2000. p. 172-183.

CORREIA, Hélia. Insânia. Lisboa: Relógio D’Água, 1996.

DURAS, Marguerite. Escrever. Trad. Rubens Figueiredo. Rio de Janeiro: Rocco, 1994.

FERREIRA, Aurélio Buarque de Holanda. Mini Aurélio - século XXI. Rio de Janeiro: Nova Fronteira, 2001.

HOUAISS, Antônio; VILLAR, Mauro; FRANCO, Francisco Manoel de Mello.. Dicionário eletrônico Houaiss da língua portuguesa. Rio de Janeiro: Objetiva/Instituto Antonio Houaiss, 2001.

MACHADO, José Pedro. Dicionário etimológico da língua portuguesa. 4. ed. Lisboa: Livros Horizonte, 1987. 